\title{
Patterns of opioid prescribing by dentists in a pediatric population: a retrospective observational study
}

\author{
UPDATED VERSION, Oct. 17, 2019
}

\author{
Debora C. Matthews DDS MSc, Martha G.S. Brillant PhD, Kudirat O. Jimoh MDPH MPerio, \\ Winston Singleton MHI MD, Pamela McLean-Veysey BSc Pharm, Ingrid Sketris PharmD MPA(HSA)
}

\section{Abstract}

Background: Dentists are regular prescribers of opioid analgesic medications; however, there are few published data on their prescribing practices for children. The aim of this study was to assess opioid prescribing practices of dentists for pediatric patients.

Methods: We conducted a retrospective study (2011/12 to 2017/18) using administrative health data of opioid prescribing practices of dentists in Nova Scotia for children and adolescents (age < $18 \mathrm{yr}$ ). The main variables of interest were opioid "type" and "load" dentists prescribed (number of dispensed prescriptions/yr, days supplied/prescription and dosage/d per prescription in milligrams of morphine equivalents [MME]).

Results: Dentists accounted for a mean of 18.3\% (standard deviation 1.5\%) of all opioid prescribers for the pediatric population annually but were responsible for $59.9 \%$ of all opioid prescriptions and $48.6 \%$ of total MME dispensed during the 7 -year study period. Oral and maxillofacial surgeons were responsible for $80.7 \%$ of all dental-related opioids dispensed. Codeine was most frequently prescribed $(78.6 \%$ of total $\mathrm{MME})$, followed by oxycodone $(11.1 \%)$. There were significant downward trends over the study period in the total amount of opioid analgesics dispensed $(r=-0.903, p<0.01)$, primarily due to a reduction in the total amount of codeine dispensed and number of days supplied per prescription $(r=-0.837, p<0.05)$. Few opioids were dispensed to children less than 12 years.

Interpretation: Dentists in Nova Scotia reduced prescriptions of opioids in the pediatric population between 2011/12 and 2017/18, which may indicate that current opioid prescribing principles are influencing dentists' prescribing habits. Nonetheless, patients and parents should receive appropriate counselling as to the proper use, risks, storage and potential for misuse of opioids when prescribed.

\footnotetext{
n 2017, there were over 4000 apparently opioid-related deaths in Canada, more than the number of Canadians who died at the height of the HIV epidemic, in $1995 .{ }^{1}$ The fastest growing rate of hospital admissions due to opioid poisoning over the past 10 years in Canada was among people aged $15-24$ years, with a $62 \%$ increase in admissions in this age group between 2007/08 and 2014/15. ${ }^{2}$ This has serious implications for health care systems, as well as for the people affected and their families.

Early exposure to opioids has been associated with higher rates of subsequent opioid use, abuse and overdose. $^{3-5}$ Despite opioid product monographs that include Health Canada warnings or state that use is not recommended in patients less than age 18 years, ${ }^{6}$ advisories regarding adverse events related to opioid use in pediatric patients and warnings about the use of codeine-containing products in children under 12 years of age, ${ }^{7}$ many adolescents and young adults are first exposed to opioids by
}

dentists ${ }^{8}$ who are the most frequent prescribers of opioids to children and adolescents in many jurisdictions. ${ }^{8-12}$

There are sparse data in the literature regarding the frequency and duration of opioid analgesics prescribed by dentists for children. Therefore, the primary objective of this study was to identify the opioid prescribing patterns of dentists in Nova Scotia to patients less than 18 years old for the period Apr. 1, 2011, to Mar. 31, 2018; a secondary objective was to compare the data to recent dental pain management recommendations. ${ }^{13,14}$

\section{Competing interests: None declared.}

This article has been peer reviewed.

Correspondence to: Debora Matthews, debora.matthews@dal.ca CMAJ Open 2019. DOI:10.9778/cmajo.20190021 


\section{Methods}

\section{Design}

The study was a retrospective analysis of administrative health data from the Nova Scotia Prescription Monitoring Program (www.nspmp.ca/about.php). ${ }^{15}$

\section{Data source}

The Nova Scotia Prescription Monitoring Program collects information on all monitored medications dispensed at community pharmacies throughout Nova Scotia for people of all ages and maintains records of controlled drugs listed under the schedules of the Canadian Controlled Drugs and Substances Act, including opioid and opioid combinations. ${ }^{16}$ Provincial legislation requires all prescriptions for monitored drugs filled in a community pharmacy in Nova Scotia to be sent to the Nova Scotia Prescription Monitoring Program. The program receives data through multiple daily data feeds via an online Drug Information System. For the current study, the monitoring program provided deidentified aggregate data on prescriptions dispensed for 7 consecutive fiscal years (2011/12 to 2017/18). Records selected from the data set were oral opioid analgesics and combinations (Appendix 1, available at www. cmajopen.ca/content/7/3/E/497/suppl/DC1) prescribed by dentists or oral and maxillofacial surgeons and dispensed to patients less than 18 years old on the date the prescription was filled. The Anatomic Therapeutic Chemical Classification System $\operatorname{codes}^{17}$ for the opioids used are presented in Appendix 1.

\section{Variables of interest}

The variables extracted from the data ${ }^{18}$ were days supplied per prescription, dosage per day per prescription (in milligrams of morphine equivalents [MME]) and opioid type prescribed (codeine, hydromorphone, meperidine, morphine or oxycodone). We calculated MME using conversion factors from the Canadian guideline for opioid therapy and chronic noncancer pain. ${ }^{19,20}$ Other variables included patient age cohort $(<12 \mathrm{yr}$, 12-17 yr), prescriber specialty (general dentist, oral and maxillofacial surgeon, other dental specialty), year of graduation from dental school, location (rural or urban, based on the second character of the postal $\operatorname{code}^{21}$ ), number of prescriptions dispensed per year per dental prescriber and mean number of dispensations per patient. We also calculated the proportion of total opioids dispensed during the study period prescribed by dentists (by MME and number of prescriptions) and the proportion of all opioid prescribers in the province who were dentists. We calculated the proportion of licensed dentists in Nova Scotia who prescribed opioids using the total number of dentists licensed in the province over each fiscal year as the denominator (information provided by the Provincial Dental Board of Nova Scotia).

\section{Statistical analysis}

Data were provided by the Nova Scotia Prescription Monitoring Program in aggregate form (aggregated by year dispensed). We used SPSS v21 software (IBM Corporation) to analyze aggregate data. We used Pearson correlation analysis to assess linear trends in total dosage, dosage per prescription, days supplied per prescription, number of prescriptions dispensed per patient and number of prescriptions per year per dentist, over the 7-year study period. We used repeatedmeasures analysis of variance to compare graduation year cohorts on their number of prescriptions per year per dentist. We used the paired-sample $t$ test to compare the mean number of prescriptions per year between urban and rural dentists and the prescribing patterns of general dentists versus oral and maxillofacial surgeons. Year dispensed was used as the unit of analysis.

\section{Ethical approval}

The study was approved by the Dalhousie Health Sciences Research Ethics Board.

\section{Results}

\section{Dental prescriber characteristics}

The number of dentists who prescribed opioids dispensed to children less than age 18 years in Nova Scotia during the study period ranged from 72 to 121 (Table 1). The majority of dentists were located in urban areas (mean $87.7 \%$ [standard deviation (SD) $2.7 \%]$ ), and there were more general dentists than specialists (mean $74.3 \%$ [SD 5.1\%] v. $25.7 \%$ [5.1\%]). More than a third had graduated from dental school before 1991 (Table 1).

\section{Proportion of dispensed opioids prescribed by dentists}

During the study period, 27652 opioid prescriptions were dispensed to children and adolescents, of which $16573(59.9 \%)$ were prescribed by dentists/dental specialists. These dental prescriptions accounted for $48.6 \%$ of the total MME dispensed to children and adolescents in Nova Scotia over the study period.

The total number of prescribers of opioids to patients less than age 18 ranged from $408(2017 / 18)$ to $694(2011 / 12)$. Dentists represented a mean of $18.3 \%$ (SD 1.5\%) of opioid prescribers. Of the total number of licensed dentists in the province during the study period, $12.9 \%-21.6 \%$ prescribed opioids to patients less than 18 years (Table 2). These proportions are estimates, as the number of dentists who obtained and relinquished their licences varied throughout each fiscal year. Dentists who prescribed opioids to patients aged less than 18 prescribed an average of 23.6 (SD 2.3) prescriptions per dentist per year.

\section{Types and amounts of opioids prescribed by dentists}

Codeine formulations accounted for the largest number of dental opioid prescriptions dispensed, at $83.1 \%$ (representing $78.6 \%$ of the total MME), followed by oxycodone $(10.9 \%$ [11.1\% of the total MME]). Hydromorphone accounted for $8.7 \%$ of the total MME, morphine $1.3 \%$, and meperidine $0.3 \%$ (Figures 1 and 2).

The mean daily dosage per prescription ranged between 39.72 and 41.36 MME. The average number of dispensations 


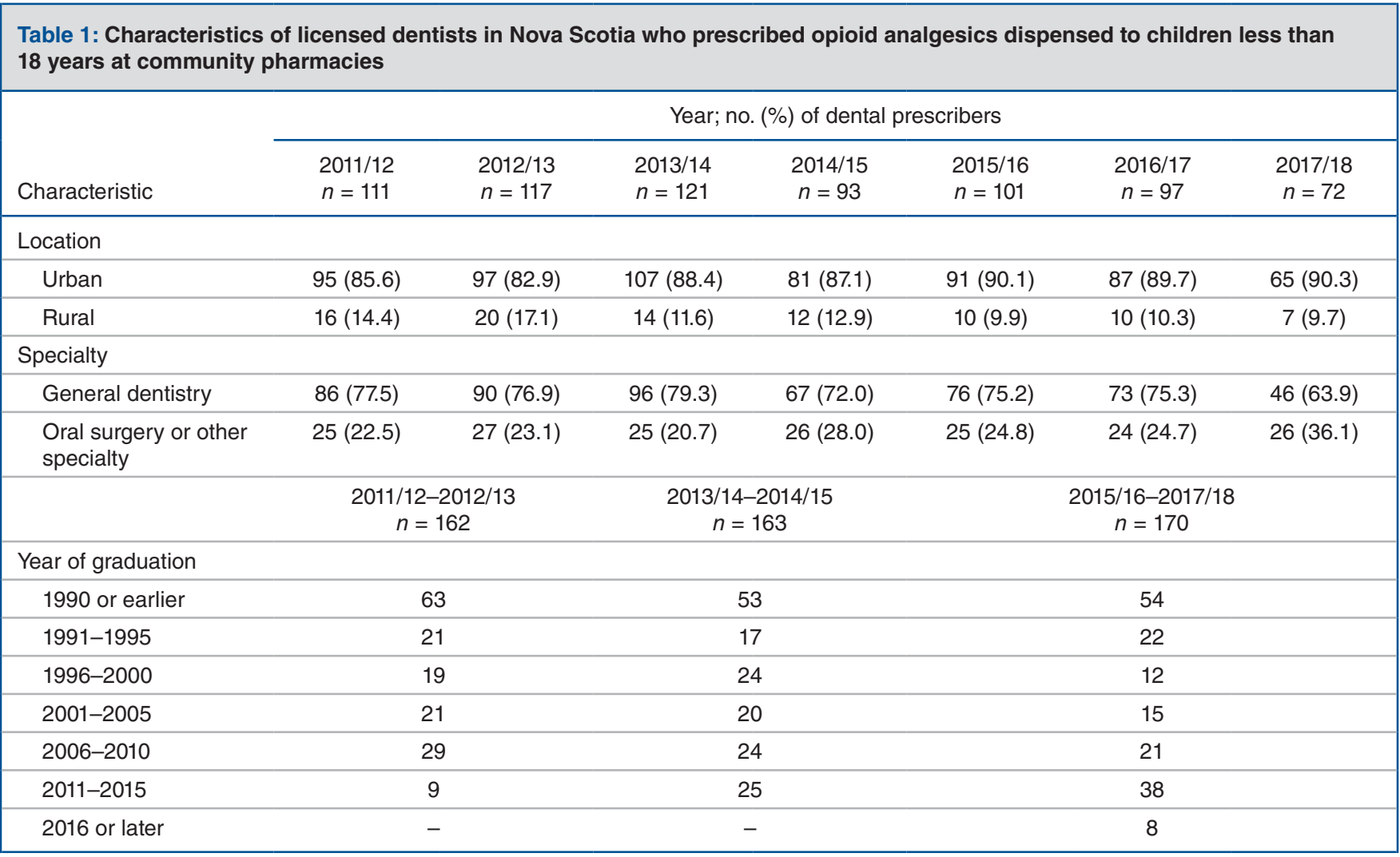

Table 2: Number and proportion of dentists who prescribed opioid analgesics dispensed to children less than 18 years

\begin{tabular}{|lccccccc|}
\hline & \multicolumn{6}{c|}{ Year; no. of dentists who prescribed opioids (\% of all licensed dentists) } \\
\cline { 2 - 8 } Patient age, yr & $2011 / 12$ & $2012 / 13$ & $2013 / 14$ & $2014 / 15$ & $2015 / 16$ & $2016 / 17$ & $2017 / 18$ \\
\hline$<12$ & $22(4.1)$ & $21(3.9)$ & $23(4.1)$ & $21(3.9)$ & $22(4.1)$ & $19(3.4)$ & $20(3.6)$ \\
\hline $12-17$ & $103(19.2)$ & $108(19.9)$ & $112(20.0)$ & $85(15.6)$ & $96(17.8)$ & $90(16.2)$ & $65(11.6)$ \\
\hline All $(<18)$ & $111(20.7)$ & $117(21.5)$ & $121(21.6)$ & $93(17.1)$ & $101(18.7)$ & $97(17.5)$ & $72(12.9)$ \\
\hline
\end{tabular}

per patient ranged from 1.01 to 1.03 . The mean number of days supplied per prescription ranged from 3.28 to 3.97 .

\section{Opioids prescribed for children less than 12 years}

Very few prescriptions were dispensed to children less than age 12 years (range $42-70$ prescriptions per year) (Figure 3). These were mostly for codeine and morphine.

\section{Trends over the study period}

There were significant downward trends in the number of dentists prescribing opioids $(r=-0.818, p<0.05)$ (Table 1$)$ and total number of dental prescriptions dispensed over the study period $(r=-0.891, p<0.01)$ (Figure 2$)$; however, there were no significant trends in the mean number of prescriptions per dentist (23.3 in 2011/12 to 27.7 in $2017 / 18, r=0.503, p=0.2$ ) or mean MME dispensed per dentist (3072 in 2011/12 to 3216 in $2017 / 18, r=0.024, p=0.96$ ). There was also a downward trend in the number of days supplied per prescription $(r=$
$-0.837, p<0.05)$ but no significant change over time in the mean daily dosage per prescription $(r=0.491, p=0.3)$ or average number of dispensations per patient $(r=-0.722, p=0.07)$.

There was a significant downward trend in the total amount of opioid analgesics prescribed by dentists to patients less than age $18(r=-0.903, p<0.01)$ (Figure 1$)$. This decrease was largely due to a decline in the total amount of codeine dispensed $(r=-0.941, p<0.01)$. The amount of meperidine dispensed also decreased significantly $(r=-0.968$, $p<0.001$ ) (Figure 1).

\section{Opioid prescribing and dental specialty}

General dentists accounted for about three-quarters of dental prescribers of opioids to children less than age 18; oral surgeons and other dental specialists accounted for the remainder (Table 1). Among these prescribers, oral surgeons and other specialists wrote an average of 75.2 (SD 5.5) prescriptions per year, whereas general dentists wrote an average of 5.8 (SD 1.3) 


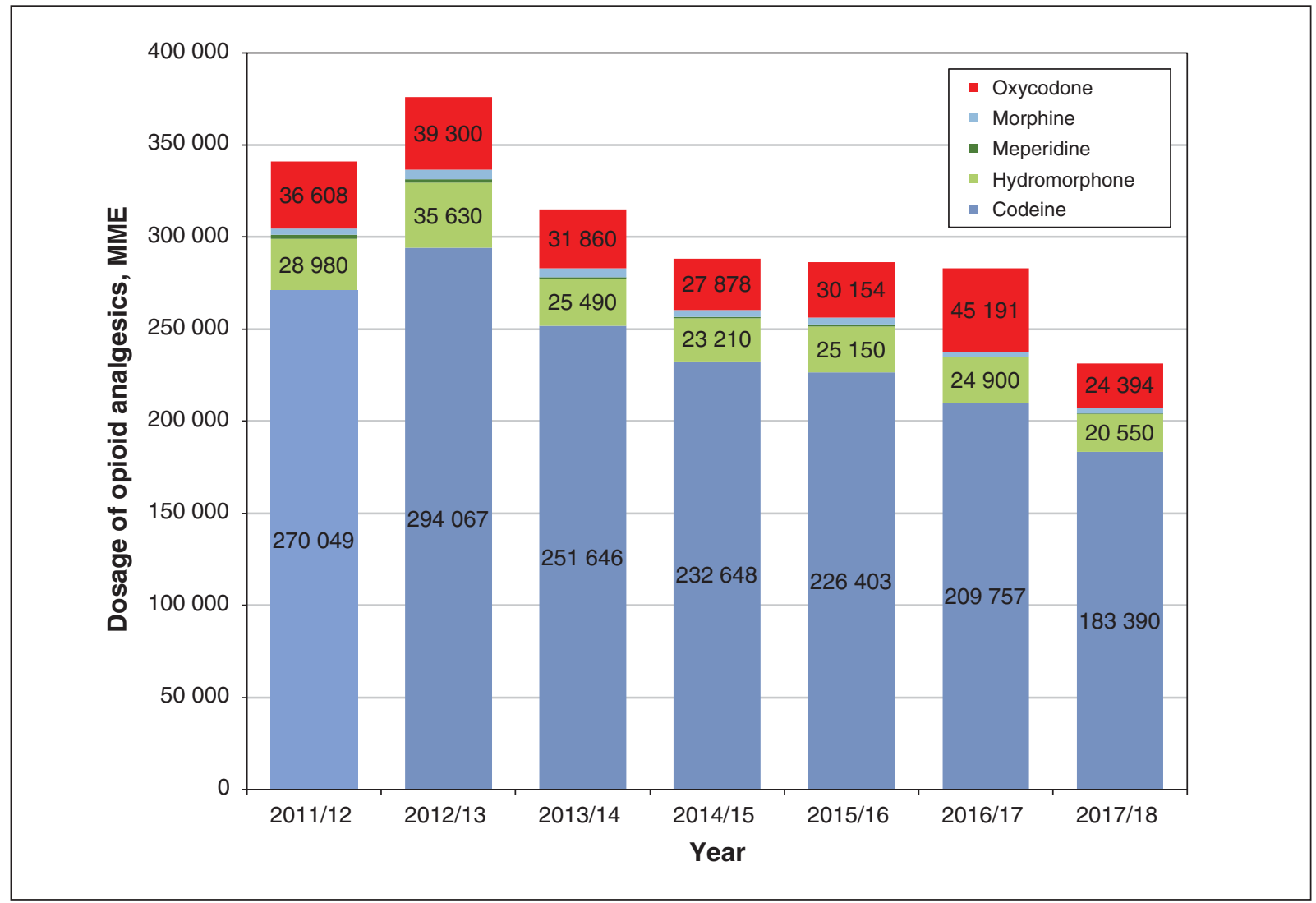

Figure 1: Total dosage (in milligrams of morphine equivalents [MME]) of opioid analgesics prescribed by dentists and dispensed to children less than 18 years at community pharmacies in Nova Scotia, 2011/12 to 2017/18.

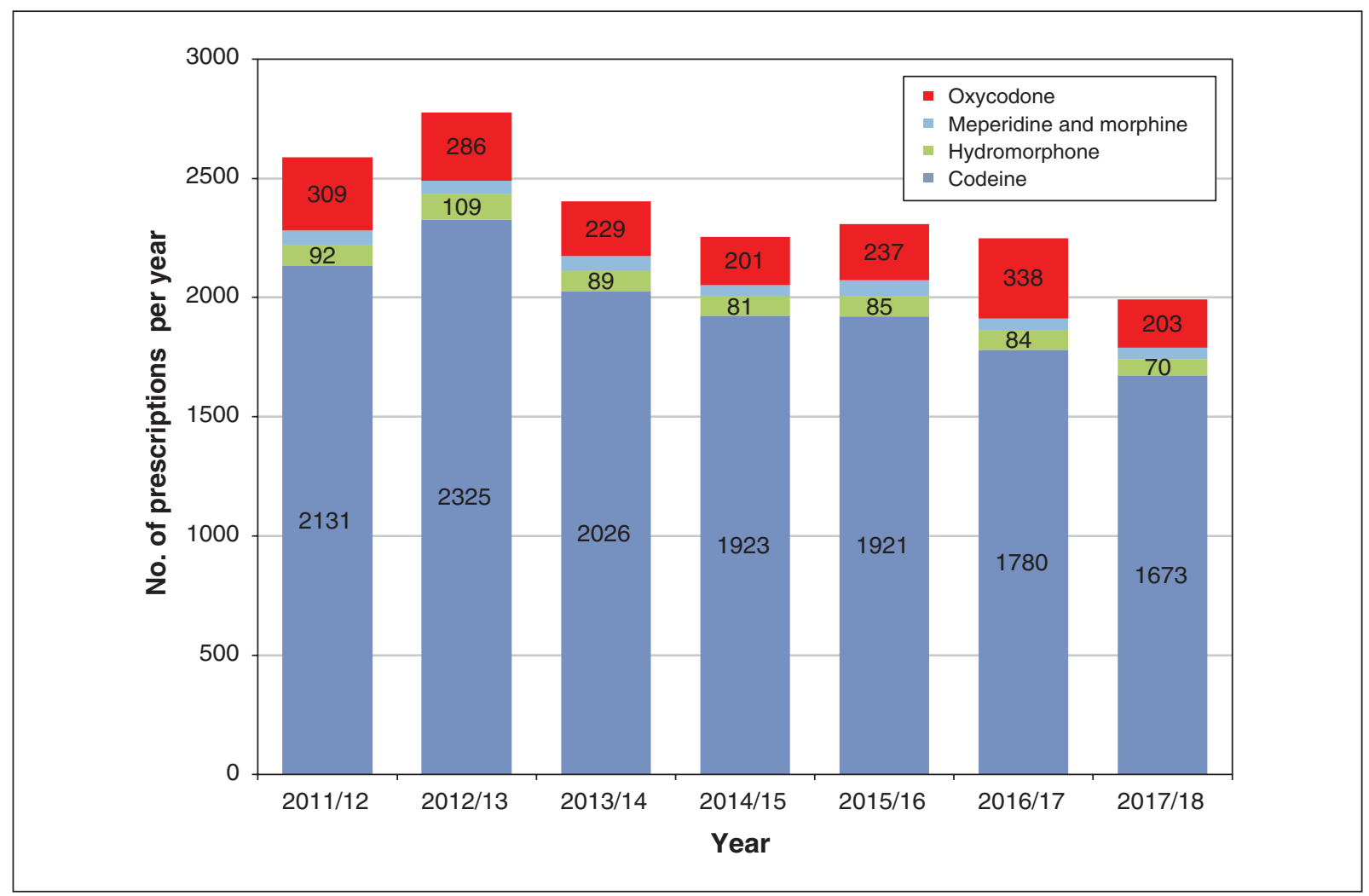

Figure 2: Number of prescriptions for opioid analgesics prescribed by dentists and dispensed to children less than 18 years. 


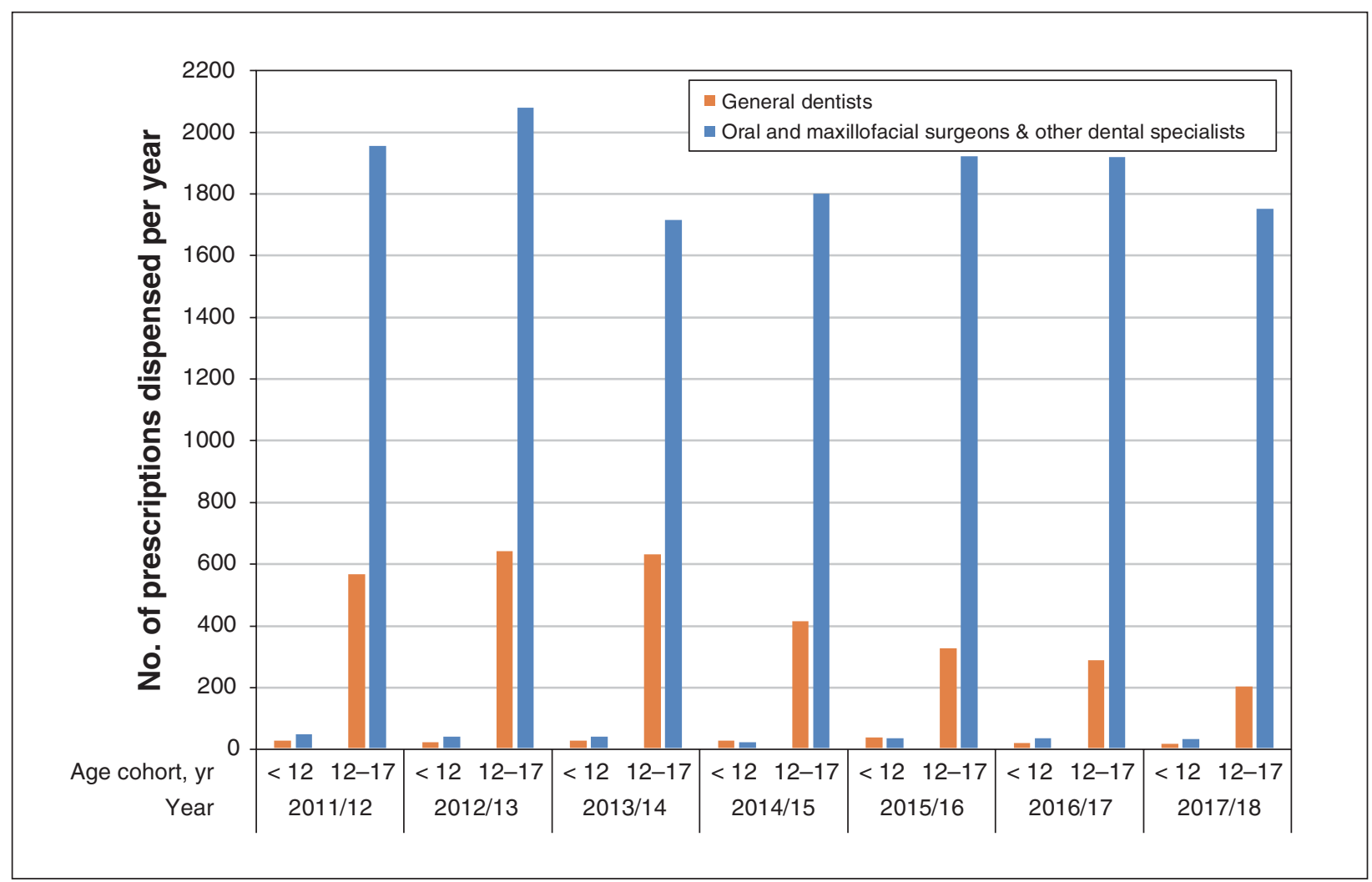

Figure 3: Number of prescriptions for opioid analgesics prescribed by dentists and dispensed to children less than 18 years, by patient age cohort and year dispensed.

prescriptions per year. Overall, oral surgeons and other specialists were responsible for $80.7 \%$ of all dental opioid prescriptions to patients less than age 18 during the study period.

On a per-prescription basis, general dentists prescribed lower dosages of codeine (mean 34.17 [SD 2.77] MME/d per prescription v. 40.21 [SD 0.84] MME/d per prescription) and had more dispensations per patient (mean 1.03 [SD 0.01] v. 1.01 [SD 0.03]) ( $p<0.01$, paired $t$ test) than oral surgeons/ specialists. There was no significant difference between the groups with in the number of days of codeine prescribed (mean 4.23 [SD 0.78] v. 3.51 [SD 0.28]) ( $p>0.05$, paired $t$ test).

There were no significant differences between general dentists and specialists in hydromorphone dosage prescribed (mean 93.63 [SD 6.22] MME/d per prescription v. 88.21 [SD 4.75] MME/d per prescription), days supplied (mean 4.15 [SD 1.90] v. 4.06 [SD 0.49]) or dispensations per patient (mean 1.05 [SD 0.11] v. 1.02 [SD 0.01)]. Similarly, there were no significant differences between the 2 groups in oxycodone dosage prescribed (mean 44.91 [SD 6.32] MME/d per prescription v. 38.51 [SD 2.31] MME/d per prescription), days supplied (mean 3.92 [SD 0.85] v. 3.74 [SD 0.34]) or dispensations per patient (mean 1.06 [SD 0.11] v. 1.01 [SD 0.004]) ( $p>$ 0.05 , paired $t$ test).

\section{Year of graduation and location of dental prescribers}

There were no statistically significant differences in the number of prescriptions per year per dentist between grad- uation year cohorts $(p>0.05$, repeated-measures analysis of variance) (Table 3$)$.

Urban dentists wrote the bulk of opioid prescriptions each year of the study (mean $92.6 \%$ [SD $0.76 \%]$ ) and wrote more prescriptions per year on an individual basis than rural dental prescribers (mean 24.87 [SD 2.44] v. 14.63 [SD 2.96]) $(p<$ 0.01, paired $t$ test) (Appendix 2, available at www.cmajopen. $\mathrm{ca} /$ content/7/3/E497/suppl/DC1).

\section{Interpretation}

Although dentists accounted for only $18 \%$ of all opioid prescribers in Nova Scotia during the study period, they were responsible for $60 \%$ of opioid prescriptions dispensed to children and adolescents less than age 18 years. This is similar to findings from South Carolina, where dentists represented a minority of prescribers $(8.9 \%)$ yet prescribed a substantial proportion (44.9\%) of initial prescription dispensations. ${ }^{22}$

Codeine was by far the opioid most frequently prescribed by dentists to patients less than age 18 in our study, followed by oxycodone and hydromorphone. Similar findings were reported by Okunseri and colleagues, ${ }^{23}$ whereas in other studies, hydrocodone was most frequently prescribed. ${ }^{24,25}$ Historically, codeine was considered an optimal orally administered analgesic for the outpatient treatment of acute pain of various causes in children, partly because of the perception that it was a safe opioid analgesic with a wide therapeutic index. In 2011, the World Health Organization deleted 


\begin{tabular}{|c|c|c|c|c|c|c|}
\hline \multirow[b]{3}{*}{ Year of graduation } & \multicolumn{6}{|c|}{ Year; no. of opioid prescriptions per year } \\
\hline & \multicolumn{2}{|c|}{$2011 / 12-2012 / 13$} & \multicolumn{2}{|c|}{$2013 / 14-2014 / 15$} & \multicolumn{2}{|c|}{$2015 / 16-2017 / 18$} \\
\hline & Total & $\begin{array}{c}\text { Mean per } \\
\text { dentist }\end{array}$ & Total & $\begin{array}{c}\text { Mean per } \\
\text { dentist }\end{array}$ & Total & $\begin{array}{r}\text { Mean pe } \\
\text { dentist }\end{array}$ \\
\hline 1990 or earlier & 1821 & 28.90 & 1266 & 23.89 & 1986 & 36.78 \\
\hline $1991-1995$ & 1566 & 74.57 & 1247 & 73.35 & 1321 & 60.05 \\
\hline 1996-2000 & 984 & 51.79 & 1155 & 48.13 & 1650 & 137.50 \\
\hline 2001-2005 & 321 & 15.29 & 285 & 14.25 & 278 & 18.53 \\
\hline $2006-2010$ & 459 & 15.83 & 448 & 18.67 & 760 & 36.19 \\
\hline $2011-2015$ & 214 & 23.78 & 256 & 10.24 & 493 & 12.97 \\
\hline 2016 or later & - & - & - & - & 63 & 7.88 \\
\hline
\end{tabular}

codeine from its list of essential medications for children, as its "efficacy and safety were questionable in an unpredictable portion of the pediatric population." 26

In 2013, Health Canada announced it had reviewed the safety of prescription pain and cough medications containing codeine and recommended against their use in children younger than 12 years. ${ }^{7}$ More recently, Health Canada announced that hydrocodone should no longer be prescribed for children less than age of 6 years. ${ }^{27}$

Inappropriate prescribing (e.g., inappropriate analgesic, overprescribing) is one of the most likely sources of nonmedical opioids. ${ }^{28}$ In a study by Groenewald and colleagues, ${ }^{24}$ children used less than $50 \%$ of opioids prescribed for acute pain, which indicates an excess number of days per prescription for many of these children. Diaries kept by parents of children aged 3-17 years showed that $14 \%$ gave no opioids and $79 \%$ had leftovers after day $3,{ }^{29}$ similar to findings from British Columbia, where $50 \%$ of children prescribed codeine formulations received prescriptions for more than 3 days of use, some up to 5 days. ${ }^{12}$ Guidelines from the Centers for Disease Control and Prevention recommend a 3-day limit for opioids prescribed to manage acute pain. ${ }^{30}$ This is also the recommendation for children less than age 15 years by Health Quality Ontario, ${ }^{31}$ which also recommends prescribing the lowest effective dosage of the least potent immediate-release opioid. Downward trends in our Nova Scotia data indicate that the mean number of days of opioids prescribed by dentists for children and adolescents is approaching this recommended limit.

In a 2007 survey of Ontario students, most (72\%) who used opioid analgesics nonmedically reported obtaining them from home. ${ }^{32}$ Unused filled prescriptions are an avenue for potential nonmedical use and diversion of prescription opioids and may contribute to accidental poisonings. This is especially true for young adults, whose first possible opioid exposure is following extraction of third molars. ${ }^{8}$ Harbaugh and colleagues ${ }^{5}$ reported that, among patients aged 13-30 years, a filled perioperative opioid prescription after wisdom tooth extraction was associated with higher odds of persistent opioid use among opioid-naive patients. Miech and colleagues ${ }^{4}$ pre- sented compelling data that adolescents with legitimate opioid use by grade 12 were $33 \%$ more likely to misuse prescription opioids after high school, even those with no history of drug use and a strong disapproval of marijuana use.

These results suggest an unrecognized risk of opioid prescribing, particularly for adolescents. This risk should be incorporated into prescribing decisions and patient/parent counselling. Although dentists regularly encounter patients with addiction, they report limited exposure to addictions training and generally lack access to systems that aid in screening, intervention, and referral to addictions treatment. ${ }^{33}$ Furthermore, limited available reports suggest that dentists do not regularly implement risk mitigation strategies — such as accessing a prescription drug monitoring program — when prescribing opioids. ${ }^{34}$

\section{Limitations}

For confidentiality reasons, we were provided with aggregate data, which precluded detailed analysis of elements such as the dose prescribed per patient. Furthermore, the data do not tell us the indication for the prescription - whether it was for acute or chronic pain, trauma, or peri- or postsurgical (extraction, oncologic surgery, cleft palate repair or orthognathic surgery). Nor do they account for opioids prescribed by emergency department physicians for dental-related pain. We were unable to determine whether opioids were the first drug of choice, as the monitoring program collected information only on controlled substances. We were also unable to standardize the prescriptions by number of visits, as dental visit data are not available. Estimates of opioid use may be underestimated. In earlier years, pharmacists did not enter the sale of Tylenol 1 (acetaminophen/codeine) in the provincial Drug Information System database. The opioid tramadol was not listed as a controlled substance during the study period. Dispensed opioids were used as a proxy for prescriptions, which may have underestimated the prevalence of opioid prescription. ${ }^{35}$ It is unknown whether this applies to opioid analgesics in Nova Scotia. A database including records of both prescribed and dispensed medications would provide an interesting perspective. 


\section{Conclusion}

This study serves to inform dentists and policy-makers on the types and dosage of opioid analgesics being prescribed for children and adolescents less than age 18 years by dentists. It may prompt dentists to reflect on and adjust their practices of opioid analgesic prescribing. The American Academy of Pediatric Dentistry states the use of opioids for pediatric patients should be rare. Rather, preemptive analgesia, profound anesthesia and nonpharmacologic techniques should be a routine part of pain management. Acetaminophen and nonsteroidal anti-inflammatory drugs should be the first-line pharmacologic choice for pain management, if not contraindicated. Opioids should be prescribed only if nonopioid treatment is ineffective, and codeine should not be prescribed to any child under the age of 12 years. Prescriptions of any opioids should generally not exceed 3 days, and the lowest effective dosage of the least-potent immediaterelease opioid should be prescribed. Patients and parents should receive appropriate counselling as to the proper use, risks, storage and potential for misuse of opioids.

\section{References}

1. National report: apparent opioid-related deaths in Canada [January 2016 to September 2018]. Ottawa: Public Health Agency of Canada; 2019. Available: https://infobase.phac-aspc.gc.ca/datalab/national-surveillance-opioid-mortality. html (accessed 2019 Apr. 8).

2. Opioid-related harms in Canada. Ottawa: Canadian Institute for Health Information; 2018. Available: https://secure.cihi.ca/free_products/opioid-related-harms -report-2018-en-web.pdf (accessed 2019 Apr. 4).

3. Schroeder AR, Dehghan M, Newman TB, et al. Association of opioid prescriptions from dental clinicians for US adolescents and young adults with subsequent opioid use and abuse. 7AMA Intern Med 2019;179:145-52.

4. Miech R, Johnston L, O'Malley PM, et al. Prescription opioids in adolescence and future opioid misuse. Pediatrics 2015;136:e1169-77.

5. Harbaugh CM, Nalliah RP, Hu HM, et al. Persistent opioid use after wisdom tooth extraction. FAMA 2018;320:504-6.

6. Compendium of pharmaceuticals and specialties. Ottawa: Canadian Pharmacists Association; updated 2018 Sept. 12. Available: https://www.pharmacists.ca/products -services/compendium-of-pharmaceuticals-and-specialties/ (accessed 2019 May 24).

7. Health Canada's review recommends codeine only be used in patients aged 12 and over. Ottawa: Health Canada; 2013. Available: www.healthycanadians.gc.ca/ recall-alert-rappel-avis/hc-sc/2013/33915a-eng.php (accessed 2018 Dec. 10).

8. Denisco RC, Kenna GA, O’Neil MG, et al. Prevention of prescription opioid abuse: the role of the dentist. 7 Am Dent Assoc 2011;142:800-10.

9. Volkow ND. Teen prescription drug abuse: a major health concern. Tenn Med 2009; 102:28-9.

10. Gupta N, Vujicic M, Blatz A. Opioid prescribing practices from 2010 through 2015 among dentists in the United States: What do claims data tell us? $7 \mathrm{Am}$ Dent Assoc 2018;149:237-45.e6.

11. Fink PB, Deyo RA, Hallvik SE, et al. Opioid prescribing patterns and patient outcomes by prescriber type in the Oregon Prescription Drug Monitoring Program. Pain Med 2018;19:2481-6.

12. Etminan M, Nouri MR, Sodhi M, et al. Dentists' prescribing of analgesics for children in British Columbia, Canada. 7 Can Dent Assoc 2017;83:h5.

13. Policy on acute pediatric dental pain management. Pediatr Dent 2017;39:99-101.

14. Canadian Association of Hospital Dentists. Hospital dentistry: eight things dentists and patients should question. Toronto: Choosing Wisely Canada; updated 2018 December. Available: https://choosingwiselycanada.org/hospital -dentistry/ (accessed 2018 Dec. 30).

15. Furlan $\mathrm{AD}$, MacDougall $\mathrm{P}$, Pellerin $\mathrm{D}$, et al. Overview of four prescription monitoring/review programs in Canada. Pain Res Manag 2014;19:102-6.

16. Government of Canada Controlled Drugs and Substances Act (S.C. 1996, c. 19). Available: https://laws.justice.gc.ca/PDF/C-38.8.pdf (accessed 2018 Dec. 19).

17. International language for drug utilization research: Anatomical Therapeutic Chemical (ATC)/Defined Daily Dose (DDD) system. Oslo: World Health Organization Collaborating Centre for Drug Statistics and Methodology, updated 2019 June 12. Available: https://www.whocc.no (accessed 2019 July 19).

18. Jimoh KO, Matthews DC, Brillant M, et al. Pattern of opioid analgesic prescription for adults by dentists in Nova Scotia, Canada. 7DR Clin Trans Res 2018;3:203-11.

19. Gutstein HB, Akil H. Opioid analgesics. In: Brunton LL, Lazo JS, Parker KL, editors. Goodman and Gilman's the pharmacological basis of therapeutics. New York: McGraw-Hill; 2006:547-90.
20. Busse JW, Craigie S, Juurlink DN, et al. Guideline for opioid therapy and chronic noncancer pain. CMA7 2017;189:E659-66.

21. Forward sortation area - definition. Ottawa: Office of the Superintendent of Bankruptcy, Innovation, Science and Economic Development Canada; 2015. Available: https://www.ic.gc.ca/eic/site/bsf-osb.nsf/eng/br03396.html (accessed 2016 Dec. 26)

22. McCauley JL, Hyer JM, Ramakrishnan VR, et al. Dental opioid prescribing and multiple opioid prescriptions among dental patients: administrative data from the South Carolina prescription drug monitoring program. 7 Am Dent Assoc 2016;147:537-44.

23. Okunseri C, Dionne RA, Gordon SM, et al. Prescription of opioid analgesics for nontraumatic dental conditions in emergency departments. Drug Alcobol Depend 2015;156:261-6.

24. Groenewald CB, Rabbitts JA, Gebert JT, et al. Trends in opioid prescriptions among children and adolescents in the United States: a nationally representative study from 1996 to 2012. Pain 2016;157:1021-7.

25. Baker JA, Avorn J, Levin R, et al. Opioid prescribing after surgical extraction of teeth in Medicaid patients, 2000-2010. 7AMA 2016;315:1653-4.

26. Unedited report of the 18th Expert Committee on the Selection and Use of Essential Medicines. Technical Report series. Geneva: World Health Organization; 2011. Available: www.who.int/selection_medicines/Complete_UNEDITED TRS_18th.pdf (accessed 2019 July 26).

27. New safety measures for prescription codeine and hydrocodone to further restrict use in children and adolescents. Ottawa: Health Canada; July 28, 2016. Available: www.healthycanadians.gc.ca/recall-alert-rappel-avis/hc-sc/2016/ 59584a-eng.php (accessed 2018 Dec. 10).

28. Fischer B, Argento E. Prescription opioid related misuse, harms, diversion and interventions in Canada: a review. Pain Physician 2012;15(Suppl 3): ES191-203

29. Voepel-Lewis T, Wagner D, Tait AR. Leftover prescription opioids after minor procedures: an unwitting source for accidental overdose in children. 7AMA Pediatr 2015;169:497-8.

30. Dowell D, Haegerich TM, Chou R. CDC guideline for prescribing opioids for chronic pain - United States, 2016. 7AMA 2016;315:1624-45.

31. Opioid prescribing for acute pain: care for people 15 years of age and older. Toronto: Health Quality Ontario; 2018. Available: www.hqontario.ca/ portals/0/documents/evidence/quality-standards/qs-opioid-acute-pain-clinician -guide-en.pdf (accessed 2018 Nov. 30).

32. Brands B, Paglia-Boak A, Sproule BA, et al. Nonmedical use of opioid analgesics among Ontario students. Can Fam Physician 2010;56:256-62.

33. McNeely J, Wright S, Matthews AG, et al. Substance-use screening and interventions in dental practices: survey of practice-based research network dentists regarding current practices, policies and barriers. 7 Am Dent Assoc 2013;144: 627-38.

34. Herman C. The Minnesota Prescription Monitoring Program. Nortbwest Dent 2011;90:33-5

35. Tamblyn R, Eguale T, Huang A, et al. Prescription opioid related misuse, harms, diversion and interventions in Canada: a review. Ann Intern Med 2014; 160:441-50.

Affiliations: Faculty of Dentistry (Matthews, Brilliant), Dalhousie University, Halifax, NS; private practice (Jimoh), Truro, NS; MetroHealth System (Singleton), Cleveland, Ohio; Nova Scotia Health Authority (McLean-Veysey); College of Pharmacy (Sketris), Dalhousie University, Halifax, NS

Contributors: Debora Matthews conceived the study. Debora Matthews, Martha Brillant, Winston Singleton, Kudirat Jimoh and Ingrid Sketris contributed to the study design, and acquired and interpreted the data. Martha Brillant, Kudirat Jimoh and Pamela McLean contributed to data analysis. Debora Matthews drafted the manuscript, and Martha Brillant, Pamela McLean and Ingrid Sketris critically revised it for important intellectual content. All of the authors approved the version to be published and agreed to be accountable for all aspects of the work.

Funding: The authors acknowledge the Drug Evaluation Alliance of Nova Scotia (DEANS) for partial funding of the study in a grant to Ingrid Sketris. Winston Singleton and Kudirat Jimoh received salary support in part from DEANS.

Acknowledgements: The authors acknowledge the Nova Scotia Prescription Monitoring Program for providing aggregate data used for this study. They also acknowledge the Provincial Dental Board of Nova Scotia for consenting to the study and providing information on the number of licensed dentists in Nova Scotia over the study period.

Supplemental information: For reviewer comments and the original submission of this manuscript, please see www.cmajopen.ca/content/7/3/ E497/suppl/DC1. 